\title{
Analysis and Design of Magnetic Shielding System for Breast Cancer Treatment with Hyperthermia Inductive Heating
}

\author{
Chanchai Thongsopa and Thanaset Thosdeekoraphat \\ School of Telecommunication Engineering, Suranaree University of Technology, Thailand \\ Correspondence should be addressed to Chanchai Thongsopa; chan@sut.ac.th and Thanaset Thosdeekoraphat; thanaset@sut.ac.th
}

Received 27 June 2013; Revised 21 September 2013; Accepted 25 September 2013

Academic Editor: Soon Yim Tan

Copyright (C) 2013 C. Thongsopa and T. Thosdeekoraphat. This is an open access article distributed under the Creative Commons Attribution License, which permits unrestricted use, distribution, and reproduction in any medium, provided the original work is properly cited.

\begin{abstract}
An analysis and design of magnetic shielding system are presented for breast cancer treatment with hyperthermia inductive heating. It is a technique to control magnetic field intensity and relocate the heating area by using a rectangular shielding with aperture. The distribution of the lossy medium was analyzed using the finite difference time domain method. Theoretical analyses investigate whether a novel shielded system is effective for controlling the magnetic field distribution or heating position. Theoretical and experimental investigations were carried out using a lossy medium. The inductive applicator is a ferrite core with diameter of $7 \mathrm{~cm}$, excited by $4 \mathrm{MHz}$ signal and a maximum output power of $750 \mathrm{~W}$. The results show that size of heating region can be controlled by varying the aperture size. Moreover, the investigation result revealed that the position of heating region can be relocated by changing the orientation of the ferrite core with shielded system in $x$-axis direction. The advantage of the magnetic shielding system is that it can be applied to prevent the side effects of hyperthermia cancer treatment by inductive heating.
\end{abstract}

\section{Introduction}

At present, cancer is one of leading causes of population death worldwide. Cancer is the uncontrolled growth and spread of cells. It can affect almost any part of the body, especially breast cancer because breast cancer has been increasing worldwide every year. Therefore, it is desirable to remove the cancer from the human body as soon as possible. Cancer can be treated effectively by various methods such as surgical excision, chemotherapy, and radiotherapy including hyperthermia [15] which is one of noninvasive techniques. The demands for noninvasive cancer treatment by hyperthermia heating are rapidly growing [6-13]. There are few techniques for noninvasive deep hyperthermia [14-17]. Most of microwave heating methods could not be used for deep hyperthermia due to skin depth effect. Low frequency technique is possible for deep treatment, though. The temperature in a cancer cell can be increased by induction [18-26]. To induce heat in the cancer cell, strong magnetic field has to penetrate the cancer cell to generate eddy current in the cell which can be visualized as electric loss. The eddy current will increase the cell temperature. The temperature of normal cells due to eddy current is constant since the cancer cell is lower than conductive than normal cell. Nevertheless, the direction of magnetic field is important for localizing the heating region. Because of high intensity magnetic field will have side effects on neighbouring normal cells, which can be devastating to normal cells $[27,28]$. A magnetic shielded system has become an important topic for hyperthermia inductive heating because it can reduce the side effects on neighbouring normal cells from magnetic field.

Moreover, the magnetic field intensity is crucial for hyperthermia treatment since it controls tissue temperature. It has been shown that magnetic core orientation and position can control the field distribution in both horizontal and vertical directions [29]. To concentrate magnetic field in a specific region, a shielding system was installed at the magnetic core. The location of heating can be controlled by moving the ferrite core. The shielding system in [29] utilizing two metal plates to control the vertical magnetic field to controlling heating position. One metal plate was placed between two ferrite cores, and the other two metal plates were placed close to the ferrite cores. This configuration provides control over the vertical field, and hence, the heating location 
can be determined by the ferrite cores location. However, the magnetic field will leak through the unshielded side of the ferrite cores. The leakage of magnetic field results in difficulty of controlling the heating area and also affects normal cells nearby. Radiotherapy for breast cancer requires regional heating with specific temperature [30]. The temperature is directly proportional to magnetic field intensity.

In this paper, we presented an analysis and design of magnetic shielding system for breast cancer treatment with hyperthermia inductive heating. This paper will analyze the effects of magnetic shielded system on heating area and location of induction heating for breast cancer hyperthermia treatment; what the articles presented here consists of numerical simulations and experiments. The distribution of the lossy medium was analyzed using the finite difference time domain method. The inductive applicator is a ferrite core with diameter of $7 \mathrm{~cm}$, excited by $4 \mathrm{MHz}$ signal and a maximum output power of $750 \mathrm{~W}$. These theoretical and experimental investigations were carried out using an agar phantom. It is difficult to limit heating area when the applicator's ferrite cores are unshielded. The results show that the size of heating region can be controlled by varying the aperture size of the shielded system. However, the heating efficiency is reduced as the aperture size decreases. If the small heating area is needed, it may require longer treatment time. In addition, the heating location can be varied by changing ferrite core orientation. By moving the orientation of the ferrite core in $x$-axis direction, the heating location and area were altered dramatically for unshielded ferrite cores, whereas the heating position and area are slightly different for shielded cores. The results show that the heating position can be relocated from the left to the right of the agar phantom by changing the orientation of the ferrite core with shielded system. The cores' vertical position has almost no effect on the heating area and position for shielded cores. In contrast, heating area and position are difficult to predict when unshielded cores are used. The proposed magnetic field shielding system is suitable for preventing the side effects of hyperthermia cancer treatment by induction heating.

\section{Concept and Construction of Shielding System}

The proposed magnetic shielding system consists of two rectangular shielding plates as shown in Figure 1. The shielding system in [29] consists of a metal plate to control the magnetic field from a single side of the core. Unlike the regional heating system in [29], the proposed shielding system controls the vertical by enclosing the ferrite core with a rectangular shield with aperture. Since placing the shielding plate at only one side of the ferrite core in [29] can control the magnetic field of only one side, it will cause magnetic field leak in the opposite side of the shielding plate. Thus, it is difficult to control the heating area. This magnetic field leakage results in spreading of the heating region that has an effect on other nearby tissues.

In this figure, a two-dimension cross-section of the analytic region is represented in order to easily understand the configuration of the shielding system analysis. The proposed

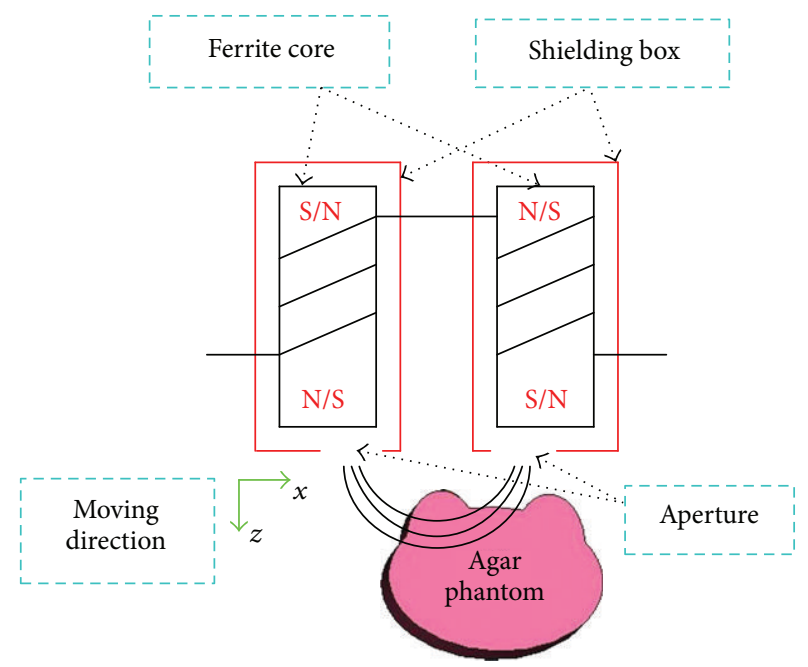

Figure 1: Schematic of shielding system. The shielding system consists of two rectangular shielding plates and controls the vertical by enclosing the ferrite core with a rectangular shield with aperture.

shielding system limits the magnetic field around the ferrite cores to confine the field in the horizontal direction. Most of the vertical magnetic field will penetrate into the heating body via the aperture, and hence the heating region size can be determined by the aperture size. Moreover, the heating position which can be relocated from the top to the bottom and the left to the right of the breast by moving the orientation of the ferrite core with rectangular shield in $x$-axis direction is illustrated in Figure 1. In addition, the design of magnetic field shielding system is necessary to take into consideration the attenuation of the magnetic field properties of the various materials used in order to spread the magnetic field over the specific area and leakage of magnetic field to the nearby areas to the fewest.

A major shielding technique used to reduce the magnetic field was divided into two ways as follows. Ferromagnetic shields give good results for small and closed shields, and they also give large field attenuation at close range to the source for open shield geometries. Highly conductive materials, on the other hand, are found to be suitable for large shield sizes. The attenuation is, however, reduced in the close vicinity of the source. In this investigation, we have selected a highly conductive material to studies, and their different materials are shown. We can regard the magnetic field as a result of the electric current flow and the magnetization of surrounding materials. The magnetic field is excited by source currents carried by conductors of various geometries. With a highly conductive shield, eddy currents arise in the metal. These currents create a field opposing the incident field. The magnetic field is in this way repulsed by the metal and forced to run parallel to the surface of the shield, yielding a low flux density outside the metal [31, 32]. Therefore, we have to consider effects of magnetic field shielding of various materials that were tested, such as copper $(\mathrm{Cu})$, lead $(\mathrm{Pb})$, steel $(\mathrm{Fe})$, and transformer steel $(\mathrm{Ck}-37)$, which have 


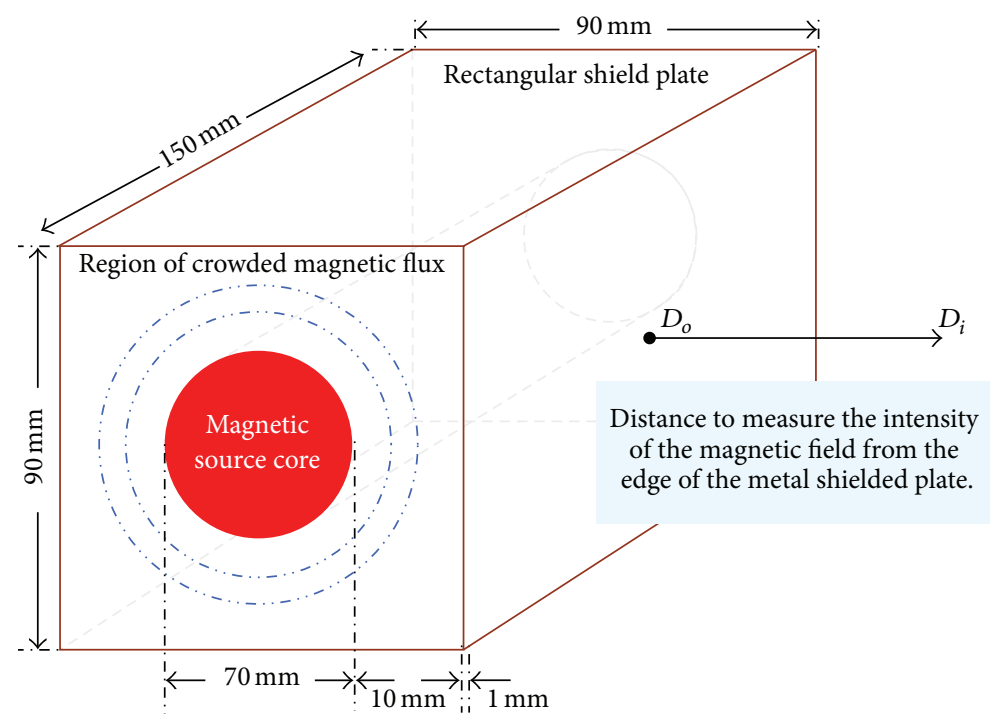

The outside area of shielding system where the magnetic flux is reduced

FIGURE 2: Schematic of rectangular shield plate and distance to measure the intensity of the magnetic field. The material used in the analyses consists of copper, lead, steel, and transformer steel $\left(D_{o}\right.$ is the edge of metal shield plate, and $D_{i}$ is the distance of magnetic field which is reduced).

TABLE 1: Properties of various materials.

\begin{tabular}{lcc}
\hline Materials & Conductivity $(\mathrm{S} / \mathrm{m})$ & Permeability \\
\hline Copper $(\mathrm{Cu})$ & $59.6 \times 10^{6}$ & 1 \\
Steel $(\mathrm{Fe})$ & $7.14 \times 10^{6}$ & 700 \\
Lead $(\mathrm{Pb})$ & $4.55 \times 10^{6}$ & 1 \\
Transformer steel (Ck-37) & $2.17 \times 10^{5}$ & 4000 \\
\hline
\end{tabular}

conductivity, relative permeability, and relative permittivity and are illustrated in Table 1.

The investigation of the effective reduction of the magnetic field for various materials was carried out in the study. To analyse the effectiveness of magnetic field shielding of materials, we specify a current source of the magnetic field $\left(J_{s}\right)$ of $1 \mathrm{~A} / \mathrm{m}^{2}$. The dimensions and schematic details of the shielding plate for analyzing the magnetic field intensity of various materials are shown in Figure 2.

Figure 2 represents the model of rectangular shield plate and distance to measure the intensity of the magnetic field [31, 33]. After that, we analyzed the effectiveness of magnetic field shielding (SE) of various materials in the following equation [34]. The shielding results are all given for a shield thickness of $1 \mathrm{~mm}$ at the frequency of $4 \mathrm{MHz}$. Consider,

$$
\mathrm{SE}(\mathrm{dB})=20 \log \left[\frac{H_{\text {unshield }}}{H_{\text {shield }}}\right] \text {, }
$$

where $H_{\text {unshield }}$ is the rms flux density without shield plate and $H_{\text {shield }}$ is the rms flux density with shield plate. Analysis of the effective shielding of magnetic field in our study is illustrated in Figure 3. The material used in the analyses consists of copper, lead, steel, and transformer steel, as mentioned above.

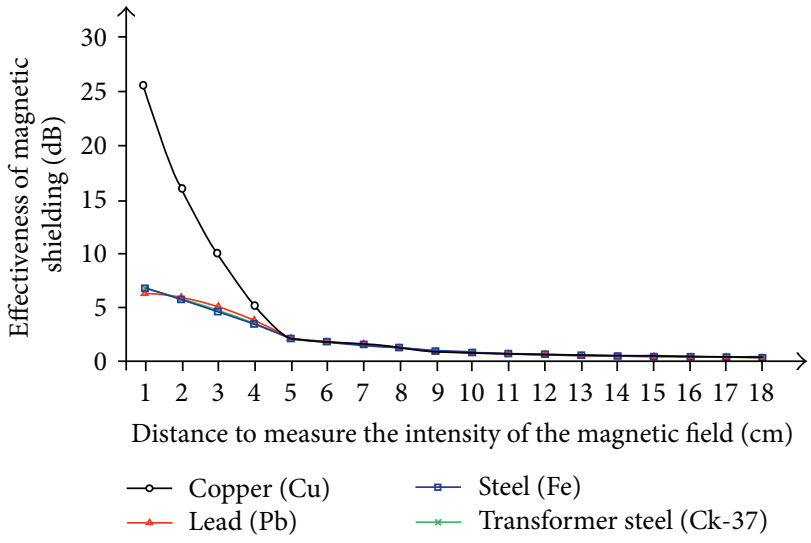

FIgURE 3: The effectiveness of magnetic field shielding of various materials that were tested. The horizontal axis represents the distance of the rectangular shielding plate, and the vertical axis shows the effectiveness of the shielding for various materials.

Figure 3 represents the effectiveness of magnetic field shielding of various materials that were tested. The horizontal axis represents the distance from the edge of the rectangular shielding plate, and the vertical axis shows the effectiveness of the shielding for various materials. The analysis found that the copper materials will be provided the most effective shield of approximately $25.47 \mathrm{~dB}$. Therefore, we chose copper as the material used for the analysis and design of magnetic shielding system. Copper is a material that can be reduced to a maximum magnetic field in order to study the characteristics of magnetic field shielding system which are applied with various aperture sizes to control the magnetic field density 

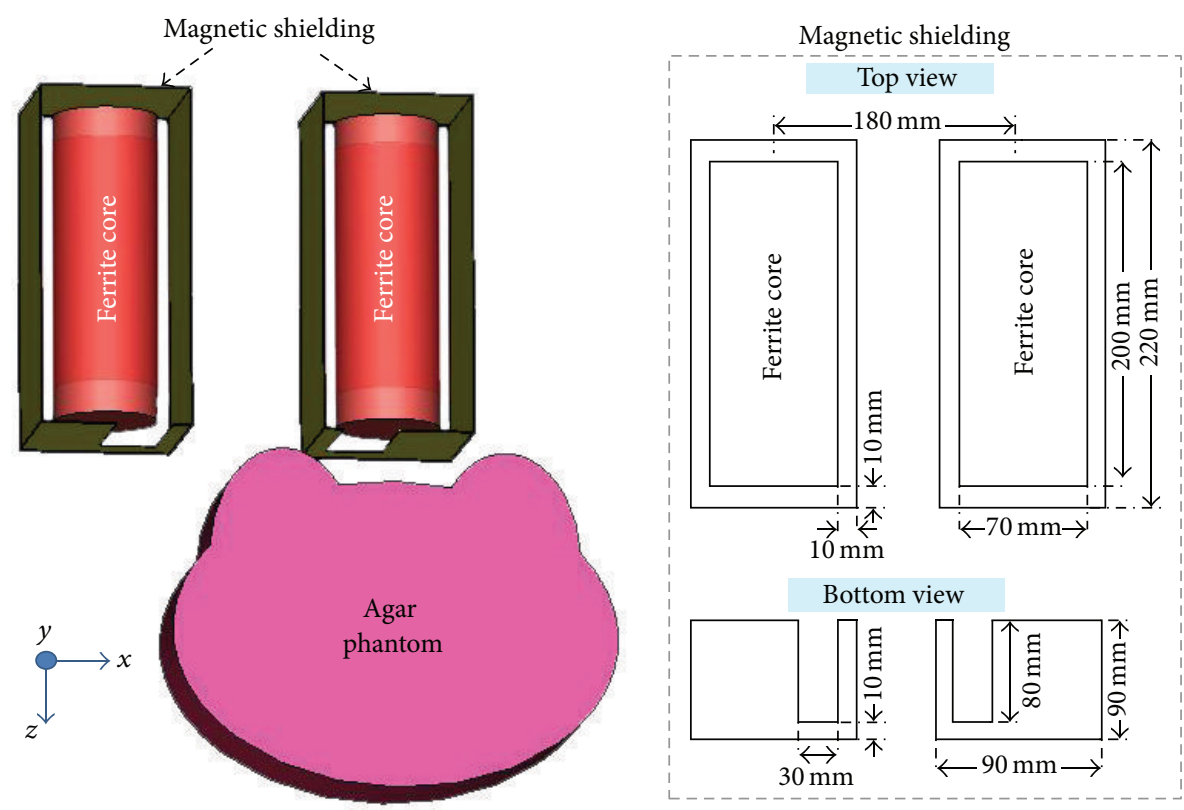

Figure 4: Analytical model of magnetic field shielding system, which represented the parameter details of the ferrite core and magnetic shielding plate for an analysis of electric loss density and temperature distribution.

and heating position appropriately. The schematic of the analytical model of magnetic field shielding system is shown in Figure 4.

Figure 4 represents the heating model which is made from agar phantom (the phantom model size is equal to $25 \times$ $20 \mathrm{~cm}$ ) with conductivity, relative permeability, and relative permittivity of $0.62 \mathrm{~S} / \mathrm{m}, 1$, and 130 , respectively. A phantom simulating a human breast was placed between a pair of ferrite cores with magnetic shield (the parameter details of ferrite cores and shielding plate are shown in Figure 4). The distance between both ferrite cores is equal to $18 \mathrm{~cm}$, by selected from a distance at the magnetic field were reduced the most from consideration of shielding plate design in Figure 3 mentioned above. The magnetic shield plate is a rectangular metal with conductivity of $59.6 e 6 \mathrm{~S} / \mathrm{m}$. The ferrite core is a highly magnetic material with $0.001 \mathrm{~S} / \mathrm{m}$ conductivity and relative permeability at 200 .

\section{Analysis of Temperature Distribution}

To determine a method of heating induction and controlling heating position, we solved Maxwell's equation and analyzed by using the three-dimensional finite difference time domain method [35-40] the following equations [41-46]:

$$
\begin{gathered}
\nabla \times E=-j \omega \mu H, \\
\nabla \times H=J_{0}+j \omega \varepsilon E+\sigma E,
\end{gathered}
$$

where $E$ is the electric field, $H$ is the magnetic field $(\mathrm{A} / \mathrm{m}), \omega$ is the radian frequency, $\mu$ is the permeability, $J_{0}$ is the forced current density $\left(\mathrm{A} / \mathrm{m}^{2}\right), \varepsilon$ is the permittivity, and $\sigma$ is the electrical conductivity $(\mathrm{S} / \mathrm{m})$. In this analysis, the following fundamental equation for vector potential $A$, which takes the eddy current into consideration, is used [28, 45]. Solving the following equation for $A$, the magnetic field and eddy current distribution are calculated as follows:

$$
\begin{gathered}
\nabla \times(\nu \nabla \times A)=J_{0}-J, \\
\nabla \times(\nu \nabla \times A)=J_{0}-\sigma \frac{\partial A}{\partial t}-\sigma \nabla \phi,
\end{gathered}
$$

where $\nu, J$, and $\phi$ represent the magnetic reluctance, and the current density $\left(\mathrm{A} / \mathrm{m}^{2}\right)$ can be calculated from magnetic field and the electric potential $(\mathrm{V})$, respectively. In the electromagnetic analysis, we derive the lowest resonant frequency of the applicator. Subsequently, the temperature distributions are observed. The temperature changes depend on the output power from the high power oscillator into the applicator systems and treatment time. The power losses in the lossy medium can be calculated from the relationship of the magnetic field and current density. Moreover, we can control the heating temperature from the external power into the applicator systems. The temperature distribution in lossy media can be calculated from bioheat transfer equation by assuming that the lossy media is human tissue or breast replica. It can be expressed as [25, 47-54]

$$
\begin{gathered}
\frac{\partial T}{\partial t}=R_{T} \nabla^{2} T+\frac{\varepsilon_{v}}{C_{p}} L_{h}\left(\frac{\partial M_{l}}{\partial t}\right)+\frac{P}{\rho C_{p}}, \\
P=J \cdot J^{*}, \\
J=-\sigma \frac{\partial A}{\partial t}-\sigma \nabla \phi \\
R_{T}=\frac{k_{t}}{\rho C_{P}},
\end{gathered}
$$


TABLE 2: Evaluating the electric loss density from changing the aperture sizes.

\begin{tabular}{|c|c|c|c|c|}
\hline $\begin{array}{l}\text { Aperture sizes of } \\
\text { shield plate }(\mathrm{cm})\end{array}$ & $\begin{array}{c}\text { Electric loss density } \\
\left(\mathrm{W} / \mathrm{m}^{3}\right)\end{array}$ & Temp. $\left({ }^{\circ} \mathrm{C}\right)$ & $\begin{array}{l}\text { Magnetic flux density } \\
(\mathrm{A} / \mathrm{m})\end{array}$ & $\begin{array}{l}\text { Effectiveness of magnetic } \\
\text { field shielding }(\mathrm{dB})\end{array}$ \\
\hline Without shielding & 295 & 70.5 & 433 & - \\
\hline 10 & 174 & 41.6 & 309 & 2.93 \\
\hline 9 & 169 & 40.4 & 295 & 3.33 \\
\hline 8 & 154 & 36.8 & 279 & 3.82 \\
\hline 7 & 148 & 35.4 & 278 & 3.84 \\
\hline 6 & 134 & 32.0 & 276 & 3.91 \\
\hline 5 & 132 & 31.5 & 275 & 3.94 \\
\hline 4 & 129 & 30.8 & 273 & 4.00 \\
\hline 3 & 108 & 25.8 & 271 & 4.07 \\
\hline
\end{tabular}

where $T$ is the temperature $\left({ }^{\circ} \mathrm{C}\right), t$ is the heating time $(\mathrm{s})$, $R_{T}$ is the distribution temperature $\left(\mathrm{m}^{2} \cdot \mathrm{s}^{-1}\right), \varepsilon_{v}$ is the liquid water flow ratio to the moisture transfer $\left(\mathrm{kg}^{-1}\right), C_{p}$ is the specific heat capacity of an object $\left(4.18 \mathrm{~J} \cdot \mathrm{kg}^{-1} \cdot{ }^{\circ} \mathrm{C}^{-1}\right), L_{h}$ is the latent heat of vaporization $\left(\mathrm{kJ} \cdot \mathrm{kg}^{-1}\right), M_{l}$ is the mass of liquid $(\mathrm{kg}), P$ is the heat source of distribution $\left(\mathrm{W} \cdot \mathrm{m}^{-3}\right)$ calculated from current density of magnetic field, and $\rho$ is the local physical density of tissue $\left(1000 \mathrm{~g} \cdot \mathrm{m}^{-3}\right)$. The simulation of induction heating was conducted by analyzing eddy current distribution of the inductive applicator which is a ferrite core, and it will be discussed in the next section.

\section{Numerical Results}

In this section, we investigate the magnetic flux density, which can be controlled by varying the aperture size. In order to resolve the problem of heating region local heating can be controlled by varying the aperture size of the shielded system. Moreover, the investigation showed that the position of heating region can be relocated by changing the orientation of the ferrite core with shielded system in $x$-axis direction. For the construction of magnetic shielding system to verify the field distribution on the heating model, full wave 3D numerical simulation was performed using finite difference time domain method.

4.1. Evaluating Electric Loss Density. To find out how to control the magnetic flux and heating region, we will change aperture size to get the most excellent heating efficiency, while causing smallest magnetic flux leakage to another nearby tissue. The proposed shielding system limits the magnetic flux around the ferrite cores to confine the field between two ferrite cores. It is a technique to control magnetic field intensity and relocate the heating area by using a rectangular metal shielding with aperture. The demonstration shows that the magnetic field intensity can be regulated by varying the aperture size.

From these theoretical investigations, one effective method to control a heating region in the breast was found. Hence, the temperature in the heating body can be controlled by the size of shielding aperture. Electric loss density for the heating model was evaluated. The ferrite core is excited by $4 \mathrm{MHz}$ signal. The aperture sizes in the simulation are $5 \mathrm{~cm}, 7 \mathrm{~cm}$, and $8 \mathrm{~cm}$. Electric loss density images for heating region of the ferrite core without shield and with rectangular shield with all aperture sizes are shown in Figure 5.

Figure 5 represents the heating region of the ferrite cores with and without rectangular shield. The heating region has spread over the large area when the ferrite core is unshielded with rectangularly shield as shown in Figure 5(a). When the ferrite core is rectangularly shielded with various aperture sizes, the heating region size is confined in smaller area as shown in Figures 5(b)-5(d), but in Figures 5(e) and 5(f) the heating region size began to spread in wide area. It is difficult to limit or control heating area when the ferrite cores with shielding plate have the large aperture size. The heating region size is reduced when the aperture size is smaller. It can be seen that the heating region is controlled by varying the aperture size as illustrated in Table 2. The results in Table 2 are expressed in terms of the electric loss density. However, replacing the electric loss density mentioned above into the last term of (4), the heating temperature in Celsius degrees unit per time will be obtained. For example, the aperture size of $8 \mathrm{~cm}$ when changing the value of electric loss density from $154 \mathrm{~W} / \mathrm{m}^{3}$ to the form of temperature will be equal to 36.84 Celsius degrees. Nevertheless, in experiment and measurement result if the small heating area is needed, it may require longer treatment time. More treatment time may be required to heat the cancer cell to the desired temperature.

The simulations show that the heating area can be effectively controlled by using the rectangular shield with adjustable aperture size as mentioned above in Table 2. The heating area was determined by the aperture size of the rectangular shield because the heating area is proportional to the aperture size. In unshielded cores, the heating area spreads unpredictably, and, hence, it is difficult to limit the heating area when the cores are unshielded. Simulations show that the heating area can be controlled by the aperture size of rectangular shield. In contrast, heating area is difficult to predict when unshielded cores are used. From Table 2, we found that the aperture size of 8 centimeters can perform the best results because the electric loss density is high. Furthermore, it can control the leakage of the magnetic field or the effectiveness of magnetic field shielding (SE) more effectively [33]. Considering the results of Table 2 shows that 


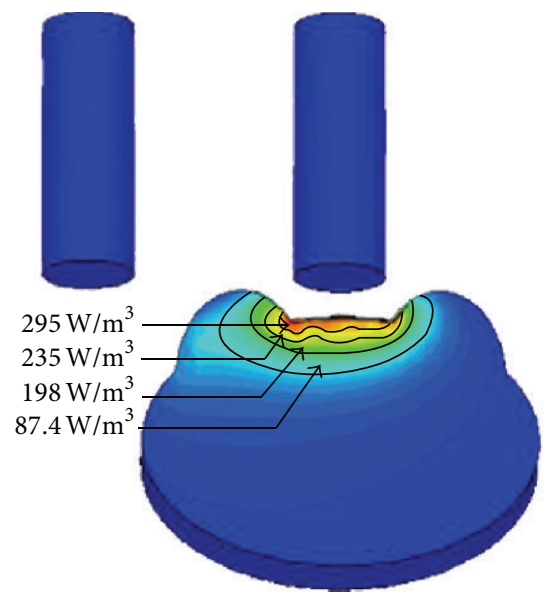

(a)

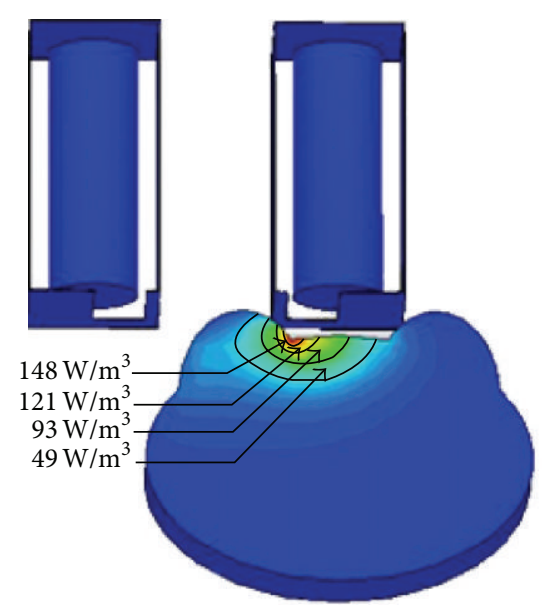

(c)

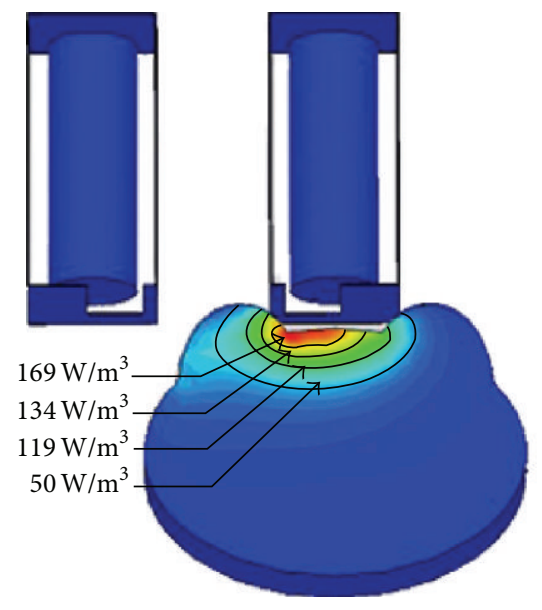

(e)
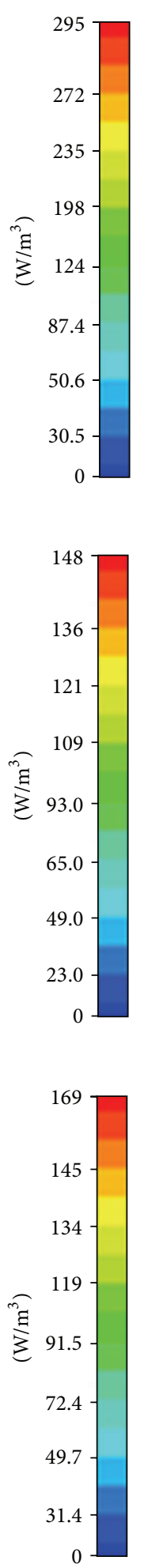

0

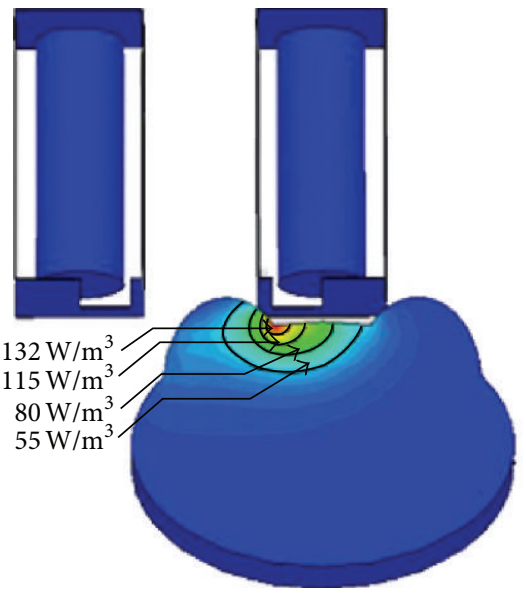

(b)

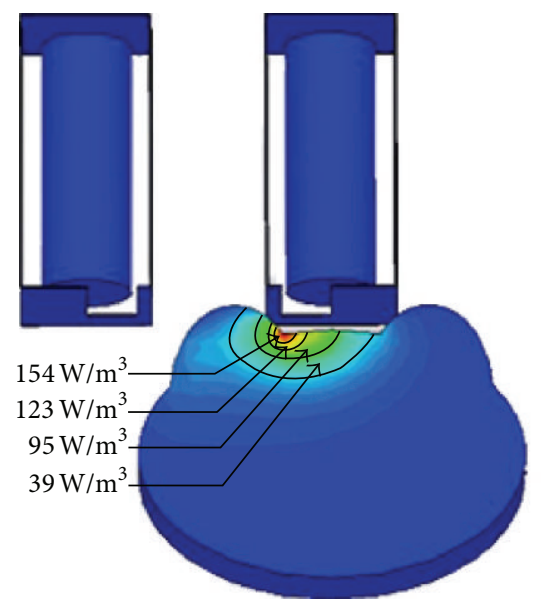

(d)
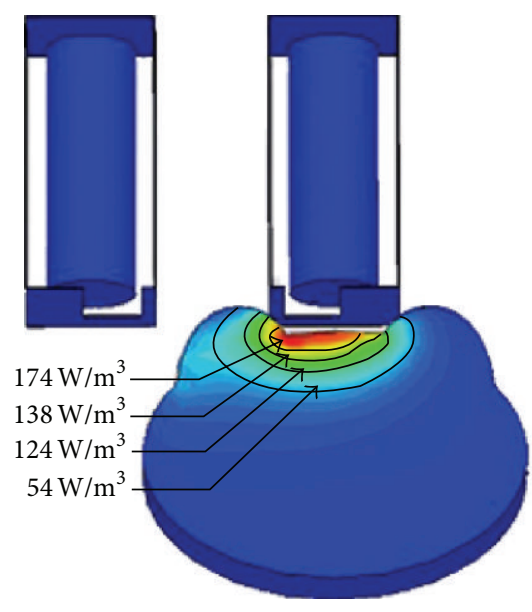

(f)
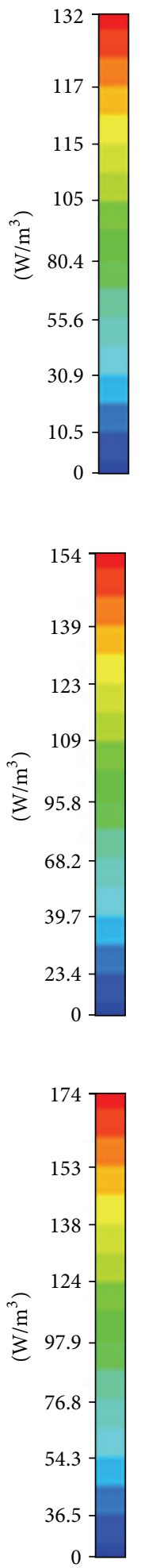

FIGURE 5: Electric loss density of the heating model for (a) ferrite core without shielding, (b) rectangular shielding with $5 \mathrm{~cm}$ aperture, (c) rectangular shielding with $7 \mathrm{~cm}$ aperture, (d) rectangular shielding with $8 \mathrm{~cm}$ aperture, (e) rectangular shielding with $9 \mathrm{~cm}$ aperture, and (f) rectangular shielding with $10 \mathrm{~cm}$ aperture. 


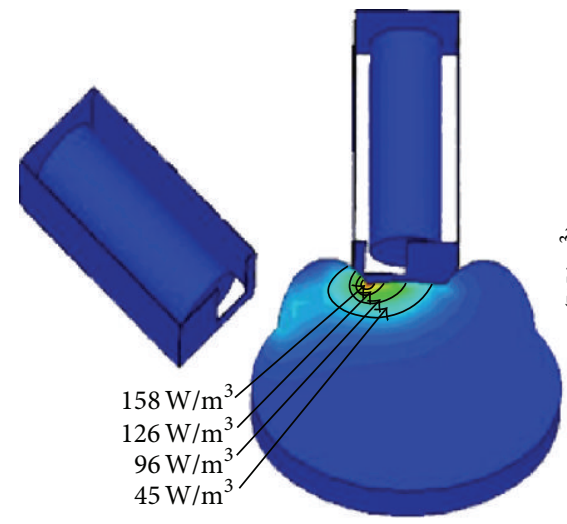

(a)

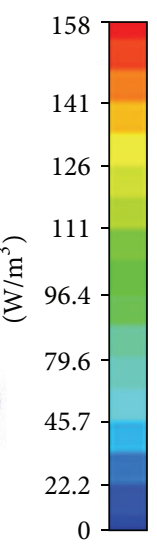

0
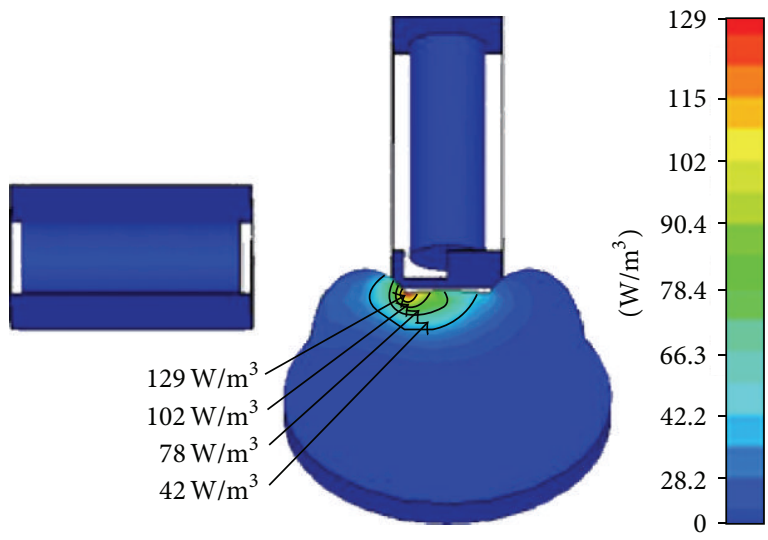

(b)

FIGURE 6: Electric loss density of the heating model for ferrite cores orientations (a) 45 degrees (b) 90 degrees.

the aperture sizes of 9 and 10 centimeters the electric loss density are having highly values. But it is difficult to limit or control heating area when the ferrite cores with shielding plate have the large aperture size. So we selected the aperture size of $8 \mathrm{~cm}$ which can perform the best results because the electric loss density is high. Furthermore, it can control the leakage of the magnetic field or the effectiveness of magnetic field shielding (SE) more effectively.

4.2. Investigating the Heating Orientation. We further investigated the heating location by changing shielded ferrite cores orientation. The ferrite cores changing the angle orientation are investigated as shown in Figure 6. For investigated the heating location by changing shielded ferrite cores orientation from original cores orientation (0-degree) to 90degree. By investigated the electric loss density or heating distribution, it will be changing the angle orientation of the ferrite core in the left hand each once equal to 5 degrees. Which in Figure 6, we have shown only two positions is 45 degrees and 90 degrees. From changing the angle orientation of the ferrite core with shielding system at 45 degrees it was found that the electric loss density is the most valuable. Furthermore, the effect of distance of the ferrite core was investigated in $x$-direction to the heating location. The result shows that the heating location can be relocated by changing the position of the ferrite core with rectangular metal shield as shown in Figure 7.

Figure 6 shows the heating region for the ferrite 45degree and 90-degree core orientation. In the shielded cores, the aperture size is $3 \times 8 \mathrm{~cm}$ in the simulation for both orientations. The maximum electric loss densities for the 45-degree and 90-degree orientation are $158 \mathrm{~W} / \mathrm{m}^{3}$ and $129 \mathrm{~W} / \mathrm{m}^{3}$, respectively. The maximum electric loss density for the 45-degree orientation is more than that for the parallel ferrite core configuration. In contrast, the electric loss density is lower for the parallel ferrite core configuration with 90-degree orientation. Moreover, the simulation results in Figure 7 show that the heating locations can be relocated from the left to the right of the breast model by changing the orientation of the ferrite core with rectangular shields in $x$-direction. The maximum electric loss density for the orientation of the both ferrite cores with rectangular shields which changed from original position to the $8 \mathrm{~cm}$ is $150 \mathrm{~W} / \mathrm{m}^{3}$. Further, the maximum electric loss density for the orientation of both ferrite cores with rectangular shields which changed from original position to $16 \mathrm{~cm}$ is $155 \mathrm{~W} / \mathrm{m}^{3}$. In this case, the heating efficiency is similar for both positions and for the original position in Figure 5(d) since the aperture size is identical.

\section{The Heating Experiment and Measurement Results}

To control the heating area and heating position, the magnetic field distributions near the breast were analyzed using the full wave 3D numerical simulation. Magnetic shielding systems with a rectangular shield with aperture were introduced to control the magnetic field and examine its shield effect. The proposed shielding system limits the magnetic field around the ferrite cores to confine the field in horizontal direction. Most of the vertical magnetic field will penetrate into the heated breast via the aperture. The construction of applicator and shielding system for verifying the numerical and simulation results is illustrated in Figure 8.

Figure 8 shows the construction of magnetic shielding system to verify the field distribution on the heating model. Shield effect of the magnetic flux density was investigated. The proposed magnetic shielding system analysis consists of high power oscillator, applicator, and agar phantom. The first part is a high power oscillator, which consists of source excited by $4 \mathrm{MHz}$ signal and power amplifier. The second part is the applicators, which includes $\mathrm{Ni}-\mathrm{Zn}$ type ferrite cores covered with rectangular shielding box with aperture sizes in the examination of $8 \mathrm{~cm}$ system model. The demonstration revealed that we can control the magnetic flux intensity and relocate the heating area by using a rectangular metal shielding with aperture. The third part is the agar phantom; it has an elliptic cylinder-like shape with a pair 


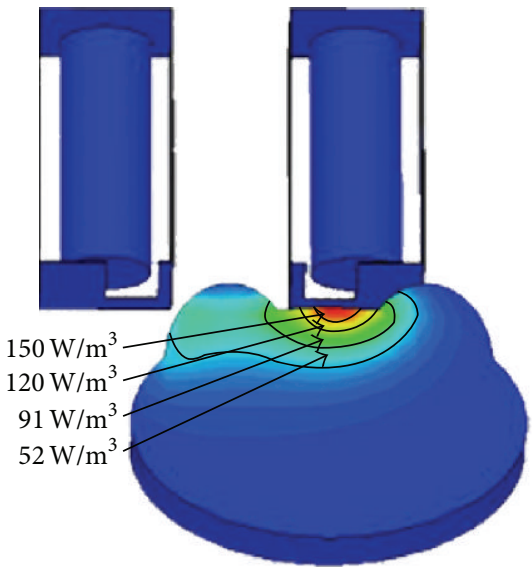

(a)
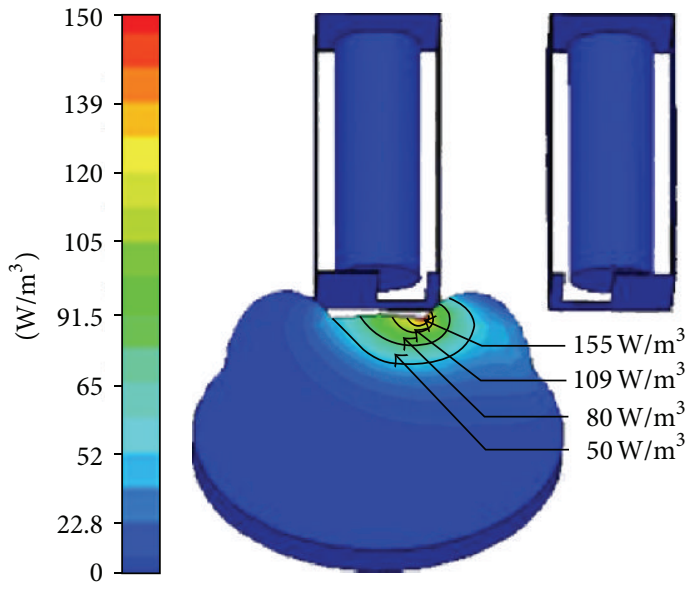

(b)

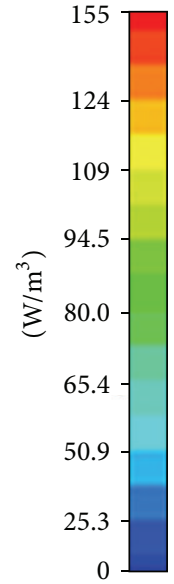

FIGURE 7: Electric loss density of the heating model for changing both ferrite cores with rectangular shields in $x$-direction. (a) The orientation of both ferrite cores with rectangular shields changed from original position to the $8 \mathrm{~cm}$ and (b) the orientation of both ferrite cores changed from the original position to $16 \mathrm{~cm}$.

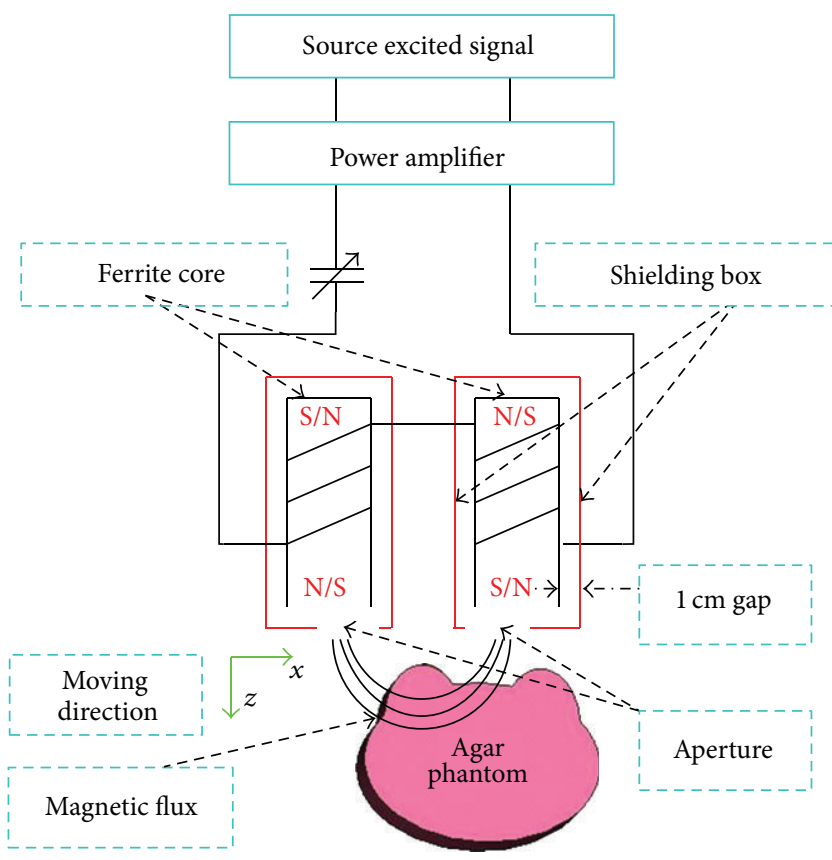

FIGURE 8: The construction of applicator and shielding system for verifying the numerical and simulation results.

of protuberances for the breasts model. The dimensions of the longer and shorter axes of the elliptic cylinder are 30 and $20 \mathrm{~cm}$, respectively. The properties of the agar phantom or artificial breasts are presented in Section 2, as already mentioned above. An agar phantom subject to the guideline assigned by the Quality Assurance Committee, Japanese Society of Hyperthermia Oncology (QAC, JASHO) was used instead of the breast. During the inductive heating, it is obviously defined according to the heating principle that only a conductive material with loss is well heated.
For the treatment of cancer by using magnetic fields, the applicator must be designed for use in spreading or induction of magnetic field. Because the cancer treatment is performed with hyperthermia inductive heating, a coil applicator is needed. A ferrite core applicator system for hyperthermia was first proposed by one of the authors to achieve effective heating and to solve irradiation problems. Since then, several kinds of ferrite core applicators have been studied and developed [11-15]. By introducing a ferrite core for the inductive applicator, a magnetic field can be concentrated between a pair of poles. Accordingly, local or regional heating becomes possible with a relatively low input power, and irradiation around the applicator is decreased, compared to the same kind of inductive applicator, which is also agreeable from the viewpoint of electromagnetic compatibility (EMC).

In this paper, the design of the induction coil or an applicator, which the applicator above mentioned is ferrite core types of 2 poles. The equation could be good series resonance in order to determine the answer by the frequency of $4 \mathrm{MHz}$. The basic principle of the series inductor, which is the total value of inductor, is equal to the sum of both inductors as shown in Figure 9.

Figure 9 shows that a typical series inductance of the inductor value is equal to the sum of the total values of each inductor. The resonance frequency is $L_{t}=L_{1}+L_{2}$. The winding number of each pole coil is $N$ turns and adjusts the value of the capacitor to be in good resonance, in which the capacitor value is $C$. The resistance is approximately $0 \mathrm{ohms}$ so that the resonant circuit gets the most excellent efficiency. Furthermore, it helps in easily understanding analysis and design of the induction coil or an applicator. The induction coils as above will spread the magnetic field between both poles. The magnetic flux moves back and forth alternately between the two poles, in which the abovementioned spread is the alternating magnetic field. In this paper we define resonance frequency of $4 \mathrm{MHz}$ and the number of pole coils 


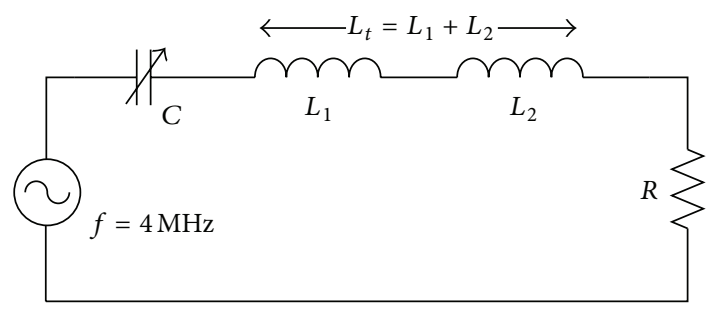

FIgURE 9: The RLC resonance equivalent circuits with the two inductors being connected in series. The resonance frequency is $4 \mathrm{MHz}$ and the two pole coils are connected in series in conditions of resonance, it will have a total inductance is $L_{t}=L_{1}+L_{2}=$ $1918.96 \mu \mathrm{H}$ and adjusts the value of the capacitor to be in good resonance, in which the capacitor value is $C=0.825 \mathrm{pF}$.

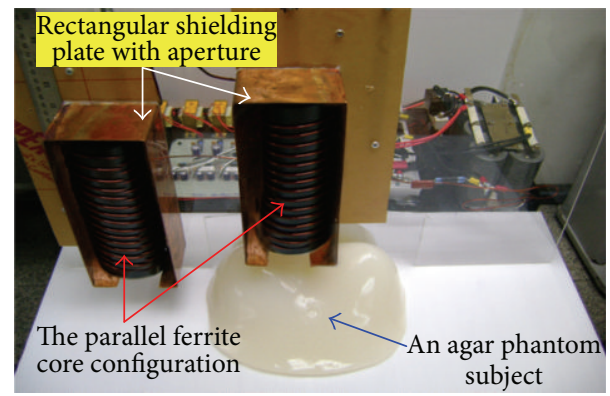

FIGURE 10: Constructions of shielding system for verifying the numerical and simulation results, in which the experiment of proposed system consists of high power oscillator, induction coils applicator with shielding plates, and agar phantom. The distance between both ferrite cores is equal to $18 \mathrm{~cm}$ from consideration of shielding plate design mentioned above.

in two series, in which the resonance frequency of the total inductor coil value is $L_{t}=L_{1}+L_{2}=1918.96 \mu \mathrm{H}$. The copper wire for inductive coil applicator design is number 13-SWG, which has cross-sectional area equal to $4.15 \mathrm{~mm}$.

The winding number of each pole coil is 14 turns and adjusts the value of the capacitor to be in good resonance, in which the capacitor value is $C=0.825 \mathrm{pF}$ as shown in Figure 10. The construction of parallel ferrite cores and rectangular shielding plates with aperture is shown. To examine these theoretical results of heating characteristics, a heating experiment was conducted. The magnetic field intensity around the ferrite cores will be limited by shielding system to confine the field in horizontal direction. Most of the vertical magnetic field will penetrate into the heating agar phantom via the aperture. The experiment of proposed system consists of high power oscillator, induction coils applicator with shielding plates, and agar phantom. The agar phantom used for the experiment is the same substance.

Figure 10 shows the construction of magnetic shielding system for breast cancer treatment with hyperthermia inductive heating. The paper experiments presented here consist of high power oscillator, induction coil applicator with shielding plates, and agar phantom. It is the experimental construction of magnetic shielding system that verifies the field distribution on the heating model. These theoretical and experimental investigations were carried out using an agar phantom. The magnetic flux density and its shield effect were investigated. The inductive applicator is a ferrite core with diameter of $7 \mathrm{~cm}$ and length of $20 \mathrm{~cm}$, excited by $4 \mathrm{MHz}$ signal, and high power oscillator has maximum output power of $750 \mathrm{~W}$ (input voltage is $50 \mathrm{~V}$ and input current is $15 \mathrm{~A}$ ). The distance between both ferrite cores is equal to $18 \mathrm{~cm}$, considering the shielding plate design in Section 2.

To examine these heating characteristics, a heating experiment was conducted. The experimental method is the same as the case mentioned above in numerical section. Figure 11 shows an experimental result of the temperature characteristics for heating region and changing distance from the initial positions of the ferrite cores. It is suggested that the magnetic shield plate plays an important role in controlling the heating region and heating position. In this experiment, the temperature distribution or the distribution of heat in the breast model can be measured by using thermograph to measure the heat value inside the breast model. After magnetic field energy flows through the lossy medium or breast model for 20 minutes, we will stop generating magnetic field (in order to prevent the magnetic field from the excited source to disturb with the thermograph used for thermal imaging). Subsequently, the temperature distribution was observed by using a thermograph (FLIR SYSTEMS Model T360).

The experiment results of the temperature distributions when the ferrite cores applicator is without shielding plates are shown in Figure 11(a). The temperature distributions at the starting position when the ferrite cores applicator is with shielding plates at the original position and the temperature distributions in the cross-section are illustrated in Figures 11(b) and 11(c), respectively. The experiment results of the temperature distributions when ferrite cores applicator with shielding plates offsets from original position in the $x$-direction by a value equal to $16 \mathrm{~cm}$ are illustrated in Figure 11(d).

Figure 11(a) shows the temperature distributions of the ferrite cores' applicator without shielding plate. Figures 11(b) and 11 (c) represent the experimental result of the temperature distributions at the initial positions of the ferrite cores with shielded plates and the temperature distributions of the ferrite cores with shielded plates in the cross-section, respectively. Further, Figure 11(d) represents the temperature distributions when the ferrite cores applicator offsets from initial positions in the $x$-direction by a value equal to $16 \mathrm{~cm}$. The maximum value of temperature of $45.5^{\circ} \mathrm{C}, 45.1^{\circ} \mathrm{C}, 44.9^{\circ} \mathrm{C}$, and $45.8^{\circ} \mathrm{C}$ is shown in Figures $11(\mathrm{a})-11(\mathrm{~d})$, respectively; it is the temperature at the cursor position. The temperature of the thermograph imaging camera setting at the starting position is in the range of $20^{\circ} \mathrm{C}$ to $46^{\circ} \mathrm{C}$, in which the magnetic energy was generated by the high power oscillator of $750 \mathrm{~W}$, excited by $4 \mathrm{MHz}$ signal. The white portion near the breast in these figures represents the highest temperature. It was found that these heating characteristics demonstrate the theoretical results. The experimental result of the temperature distributions observed by using a thermograph which is consistent with the numerical calculations results. The electric loss density of the heating model is a part of the magnetic 


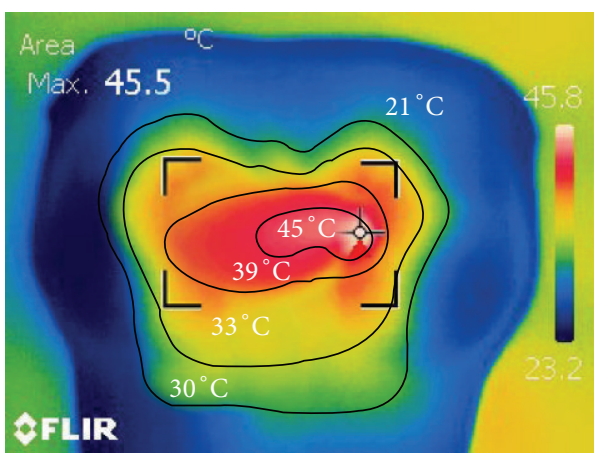

(a)

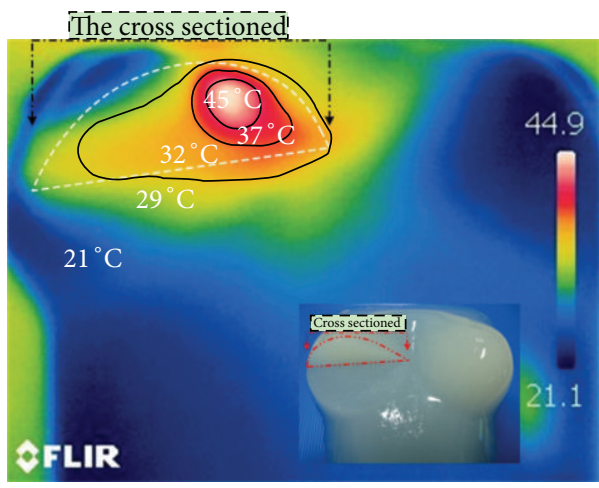

(c)

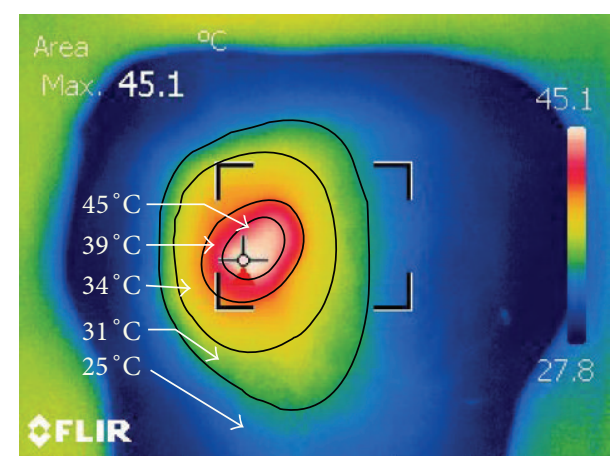

(b)

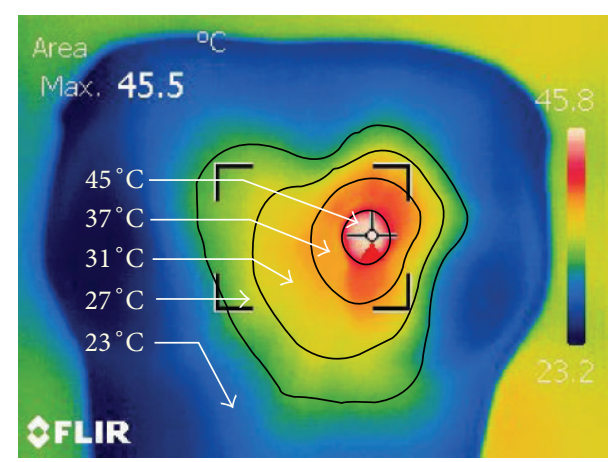

(d)

FIGURE 11: The temperature of the agar phantom: (a) the temperature distributions for the ferrite cores applicator without shielding plates, (b) the temperature distributions with shielding plates at the original position, (c) the temperature distributions in the cross-section, and (d) the temperature when the ferrite cores applicator offsets from original position in the $x$-direction by a value equal to $16 \mathrm{~cm}$.

field energy from the external source excited by $4 \mathrm{MHz}$ signal because the energy of the external electromagnetic field is directly proportional to the internal temperature of the breast model obtained from the thermograph imaging camera.

\section{Conclusion}

The effect of magnetic shielding system on heating area and the location for breast cancer treatment with hyperthermia inductive heating are presented. It is a novel technique to control magnetic field intensity and relocate the heating area by using a rectangular shielding with aperture. The distribution of the lossy medium was analyzed using the FDTD. From these investigations, we found that the aperture size of $8 \times 3$ centimeters could perform the best results because the electric loss density is high to equal, $154 \mathrm{~W} / \mathrm{m}^{3}$. Furthermore, it can control the leakage of the magnetic field more effectively. In addition, the heating location can be varied by changing ferrite core orientation. The results show that the heating position can be relocated from the left to the right of the agar. Subsequently, the heating experiment was conducted. The inductive applicator is a ferrite core with diameter of $7 \mathrm{~cm}$ and length of $20 \mathrm{~cm}$, excited by $4 \mathrm{MHz}$ signal, and a maximum output power of $750 \mathrm{~W}$. From heating experiment by using a thermograph, we found that the value of the temperature distribution in the breast model is approximately $45^{\circ} \mathrm{C}$. The proposed magnetic field shielding system is suitable to prevent the side effects of hyperthermia cancer treatment by inductive heating.

\section{Acknowledgments}

This work was supported by Suranaree University of Technology (SUT) and by the Office of the Higher Education under NRU project of Thailand. The authors deeply appreciate the valuable comments of the reviewers and recommends to be advantageous for revisions this paper.

\section{References}

[1] E. Ben Hur, M. M. Elkind, and B. V. Bronk, "Thermally enhanced radioresponse of cultured Chinese hamster cells: inhibition of repair of sublethal damage and enhancement of lethal damage," Radiation Research, vol. 58, no. 1, pp. 38-51, 1974.

[2] P. P. Antichi, N. Tokita, J. H. Kim et al., "Selective heating of coetaneous human tumors at 27. $12 \mathrm{MHz}$," IEEE Transactions on Microwave Theory and Techniques, vol. 26, no. 8, pp. 569-572, 1978.

[3] J. R. Oleson, "A review of magnetic induction methods for hyperthermia treatment of cancer," IEEE Transactions on Biomedical Engineering, vol. 31, no. 1, pp. 98-105, 1984.

[4] I. Kimura and T. Katsuki, "VLF induction heating for clinical hyperthermia," IEEE Transactions on Magnetics, vol. 22, no. 6, pp. 1897-1900, 1986. 
[5] P. Charles and P. Elliot, Handbook of Biological Effects of Electromagnetic Fields, CRC Press, New York, NY, USA, 1995.

[6] F. K. Storm, R. S. Elliott, W. H. Harrison, and D. L. Morton, "Clinical RF hyperthermia by magnetic-loop induction: a new approach to human cancer therapy," IEEE Transactions on Microwave Theory and Techniques, vol. 30, no. 8, pp. 1149-1158, 1982.

[7] H. Kato and T. Ishida, "New inductive applicator for hyperthermia," Journal of Microwave Power, vol. 18, no. 4, pp. 331-336, 1983.

[8] A. Rosen, M. A. Stuchly, and A. Vander Vorst, "Applications of RF/microwaves in medicine," IEEE Transactions on Microwave Theory and Techniques, vol. 50, no. 3, pp. 963-974, 2002.

[9] V. A. Vander, A. Rosen, and Y. Kotsuka, RF/Microwave Interaction With Biological Tissues, Wiley-IEEE, New York, NY, USA, 2006.

[10] P. R. Stauffer and S. N. Goldberg, "Introduction: thermal ablation therapy," International Journal of Hyperthermia, vol. 20, no. 7, pp. 671-677, 2004.

[11] M. Hiraoka, M. Mitsumori, N. Hiroi et al., "Developmentof RF and microwave heating equipment and clinical applications to cancer treatment in Japan," IEEE Transactions on Microwave Theory and Techniques, vol. 48, no. 1, pp. 1789-1799, 2000.

[12] Y. Kotsuka, E. Hankui, M. Hashimoto, and M. Miura, "Developmentof double-electrode applicator for localized thermal therapy," IEEE Transactions on Microwave Theory and Techniques, vol. 48, no. 1, pp. 1906-1908, 2000.

[13] P. S. Ruggera and G. Kantor, "Development of a family of RF helical coil applicators which produce transversely uniform axially distributed heating in cylindrical fat-muscle phantoms," IEEE Transactions on Biomedical Engineering, vol. 31, no. 1, pp. 98-106, 1984.

[14] Y. Kotsuka, "Development of ferrite core applicator system for deep-induction hyperthermia," IEEE Transactions on Microwave Theory and Techniques, vol. 44, no. 10, pp. 1803-1810, 1996.

[15] Y. Kotsuka and H. Okada, "Development of small and high efficiency implant for deep local hyperthermia," Japanese Journal of Hyperthermic Oncology, vol. 19, no. 1, pp. 11-22, 2003.

[16] V. D’Ambrosio and F. Dughiero, "Numerical model for RF capacitive regional deep hyperthermia in pelvic tumors," Medical and Biological Engineering and Computing, vol. 45, no. 5, pp. 459-466, 2007.

[17] S. Kuroda, N. Uchida, K. Sugimura, and H. Kato, “Thermal distribution of radio-frequency inductive hyperthermia using an inductive aperture-type applicator: evaluation of the effect of tumour size and depth," Medical and Biological Engineering and Computing, vol. 37, no. 3, pp. 285-290, 1999.

[18] J. H. Kim, E. W. Hahn, N. Tokita, and L. Z. Nisce, "Local tumor hyperthermia in combination with radiation therapy. I. Malignant cutaneous lesions," Cancer, vol. 40, no. 1, pp. 161-169, 1977.

[19] R. S. Elliott, W. H. Harrison, and F. K. Storm, "Hyperthermia: electromagnetic heating of deep-seated tumors," IEEE Transactions on Biomedical Engineering, vol. 29, no. 1, pp. 61-64, 1982.

[20] M. J. Hagmann and R. L. Levin, "Coupling efficiency of helical coil hyperthermia applications," IEEE Transactions on Biomedical Engineering, vol. 32, no. 7, pp. 539-540, 1985.

[21] J.-L. Guerquin-Kern, M. J. Hagmann, and R. L. Levin, "Experimental characterization of helical coils as hyperthermia applicators," IEEE Transactions on Biomedical Engineering, vol. 35, no. 1, pp. 46-52, 1988.
[22] P. Raskmark and J. B. Andersen, "Focused electromagnetic heating of muscle tissue," IEEE Transactions on Microwave Theory and Techniques, vol. 32, no. 8, pp. 887-888, 1984.

[23] C. A. Tiberio, L. Raganella, G. Banci, and C. Franconi, "The RF toroidal transformer as a heat delivery system for regional and focused hyperthermia," IEEE Transactions on Biomedical Engineering, vol. 35, no. 12, pp. 1077-1085, 1988.

[24] J. B. Anderson, A. Baun, K. Harmark et al., "A hyperthermia system using a new type of inductive applicator," IEEE Transactions on Biomedical Engineering, vol. 31, no. 1, pp. 212-227, 1984.

[25] F. Dughiero and S. Corazza, "Numerical simulation of thermal disposition with induction heating used for oncological hyperthermic treatment," Medical and Biological Engineering and Computing, vol. 43, no. 1, pp. 40-46, 2005.

[26] H. Rahn, S. Schenk, H. Engler et al., "Tissue model for the study of heat transition during magnetic heating treatment," IEEE Transactions on Magnetics, vol. 49, no. 1, pp. 244-249, 2013.

[27] C. Polk and E. Postow, Handbook of Biological Effects of Electromagnetic Fields, CRC Press, Boca Raton, Fla, USA, 1996.

[28] S. L. Ho, S. Niu, W. N. Fu et al., "Design and analysis of novel focused hyperthermia devices," IEEE Transactions on Magnetics, vol. 48, no. 11, pp. 3254-3257, 2012.

[29] Y. Kotsuka, M. Watanabe, M. Hosoi, I. Isono, and M. Izumi, "Development of inductive regional heating system for breast hyperthermia," IEEE Transactions on Microwave Theory and Techniques, vol. 48, no. 1, pp. 1807-1814, 2000.

[30] C. Thongsopa, A. Intarapanich, and S. Tangwachirapan, "Shielding system for breast hyperthermia inductive heating," in Proceedings of the ISEF-XIV International Symposium on Electromagnetic Fields in Mechatronics, Electrical and Electronic Engineering, Arras, France, September 2009.

[31] L. Hasselgren and J. Luomi, "Geometrical aspects of magnetic shielding at extremely low frequencies," IEEE Transactions on Electromagnetic Compatibility, vol. 37, no. 3, pp. 409-420, 1995.

[32] Y. Du, T. C. Cheng, and A. S. Farag, "Principles of powerfrequency magnetic field shielding with flat sheets in a source of long conductors," IEEE Transactions on Electromagnetic Compatibility, vol. 38, no. 3, pp. 450-459, 1996.

[33] Y. Kotsuka, H. Kayahara, K. Murano, H. Matsui, and M. Hamuro, "Local inductive heating method using novel hightemperature implant for thermal treatment of luminal organs," IEEE Transactions on Microwave Theory and Techniques, vol. 57, no. 10, pp. 2574-2580, 2009.

[34] L. Hasselgren and J. Luomi, "Geometrical aspects of magnetic shielding at extremely low frequencies," IEEE Transactions on Electromagnetic Compatibility, vol. 37, no. 3, pp. 409-420, 1995.

[35] D. Sullivan, "Three-dimensional computer simulation in deep regional hyperthermia using the finite-difference time-domain method," IEEE Transactions on Microwave Theory and Techniques, vol. 38, no. 2, pp. 204-211, 1990.

[36] K. S. Kunz and R. J. Luebbers, The Finite Difference Time Domain for Electromagnetics, CRC Press, New York, NY, USA, 1993.

[37] D. M. Sullivan, "A frequency-dependent FDTD method for biological applications," IEEE Transactions on Microwave Theory and Techniques, vol. 40, no. 3, pp. 532-539, 1992.

[38] C. Thongsopa, M. Krairiksh, A. Mearnchu, and D.-A. Srimoon, "Analysis and design of injection-locking steerable active array applicator," IEICE Transactions on Communications, vol. E85-B, no. 10, pp. 2327-2337, 2002.

[39] D. C. Dibben and A. C. Metaxas, "Finite element time domain analysis of multimode applicators using edge elements," Journal 
of Microwave Power and Electromagnetic Energy, vol. 29, no. 4, pp. 242-251, 1994.

[40] S. Bharoti and S. Ramesh, "Simulation of specific absorption rate of electromagnetic energy radiated by mobile handset in human head using FDTD method," WSEAS Transactions on Communications, vol. 2, pp. 174-180, 2003.

[41] W. Renhart, C. A. Magele, K. R. Richter, P. Wach, and R. Stollberger, "Application of eddy current formulations to magnetic resonance imaging," IEEE Transactions on Magnetics, vol. 28, no. 2, pp. 1517-1520, 1992.

[42] A. Boadi, Y. Tsuchida, T. Todaka, and M. Enokizono, "Designing of suitable construction of high-frequency induction heating coil by using finite-element method," IEEE Transactions on Magnetics, vol. 41, no. 10, pp. 4048-4050, 2005.

[43] P. A. Bottomley and E. R. Andrew, "RF magnetic field penetration, phase shift and power dissipation in biological tissue: implications for NMR imaging," Physics in Medicine and Biology, vol. 23, no. 4, pp. 630-643, 1978.

[44] N. Kuster and Q. Balzano, "Energy absorption mechanism by biological bodies in the near field of dipole antennas above 300 MHz," IEEE Transactions on Vehicular Technology, vol. 41, no. 1, pp. 17-23, 1992.

[45] C. A. Balanis, Advanced Engineering Electromagnetic, Wiley, New York, NY, USA, 1989.

[46] K. S. Yee, "Numerical solution of initial boundary value problems involving Maxwell's equations in isotropic media," IEEE Transactions on Antennas and Propagation, vol. 14, no. 3, pp. 302-307, 1966.

[47] V. Mateev, I. Marinova, Y. Saito et al., "Coupled field modeling of Ferrofluid heating in tumor tissue," IEEE Transactions on Magnetics, vol. 49, no. 5, pp. 1793-1796, 2013.

[48] V. D’Ambrosio and F. Dughiero, "Numerical model for RF capacitive regional deep hyperthermia in pelvic tumors," Medical and Biological Engineering and Computing, vol. 45, no. 5, pp. 459-466, 2007.

[49] R. B. Roemer and T. C. Cetas, "Applications of bioheat transfer simulations in hyperthermia," Cancer Research, vol. 44, no. 10, supplement, pp. 4788s-4798s, 1984.

[50] S. M. Mimoune, J. Fouladgar, A. Chentouf, and G. Develey, "A 3D impedance calculation for an induction heating system for materials with poor conductivity," IEEE Transactions on Magnetics, vol. 32, no. 3, pp. 1605-1608, 1996.

[51] N. S. Doncov and B. D. Milovanovic, "TLM modeling of the circular cylindrical cavity loaded by lossy dielectric sample of various geometric shapes," Journal of Microwave Power and Electromagnetic Energy, vol. 37, no. 4, pp. 237-247, 2002.

[52] O. P. Gandhi and J.-Y. Chen, "Electromagnetic absorption in the human head from experimental 6-GHz handheld transceivers," IEEE Transactions on Electromagnetic Compatibility, vol. 37, no. 4, pp. 547-558, 1995.

[53] A. Hadjem, D. Lautru, C. Dale, M. F. Wong, V. F. Hanna, and J. Wiart, "Study of specific absorption rate (SAR) induced in two child head models and in adult heads using mobile phones," IEEE Transactions on Microwave Theory and Techniques, vol. 53, no. 1, pp. 4-11, 2005.

[54] S. C. Gnyawali, Y. Chen, F. Wu et al., “Temperature measurement on tissue surface during laser irradiation," Medical and Biological Engineering and Computing, vol. 46, no. 2, pp. 159168, 2008. 

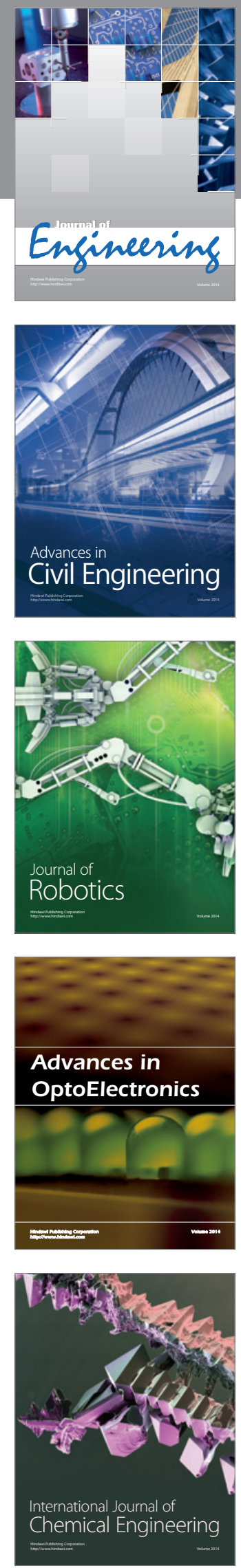

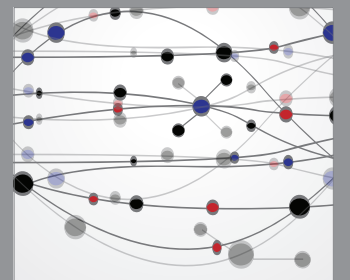

The Scientific World Journal
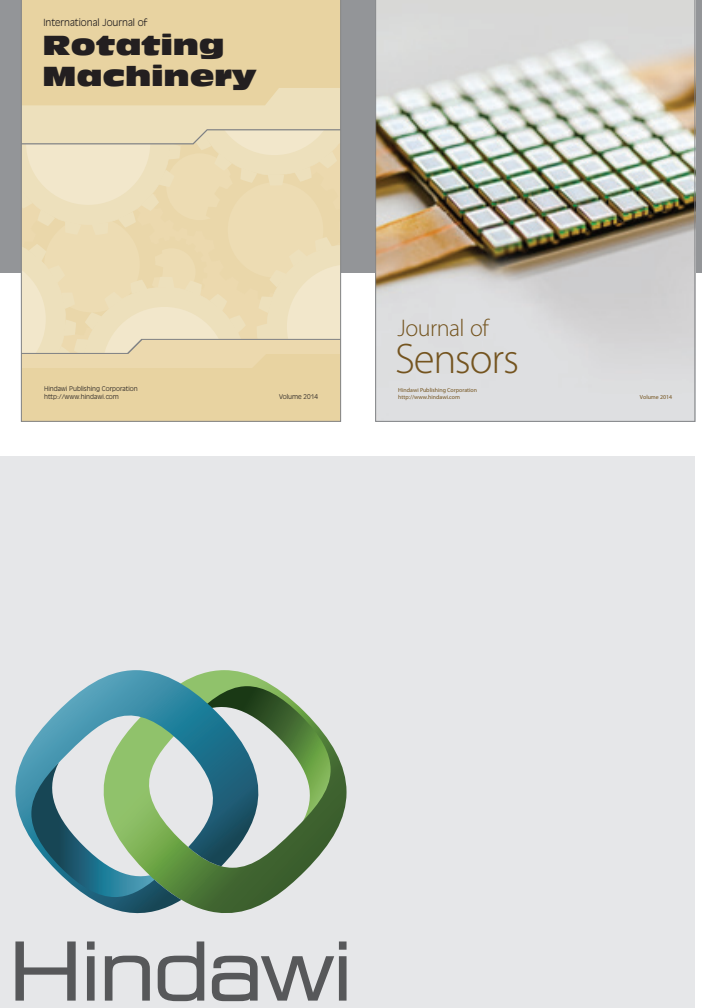

Submit your manuscripts at http://www.hindawi.com
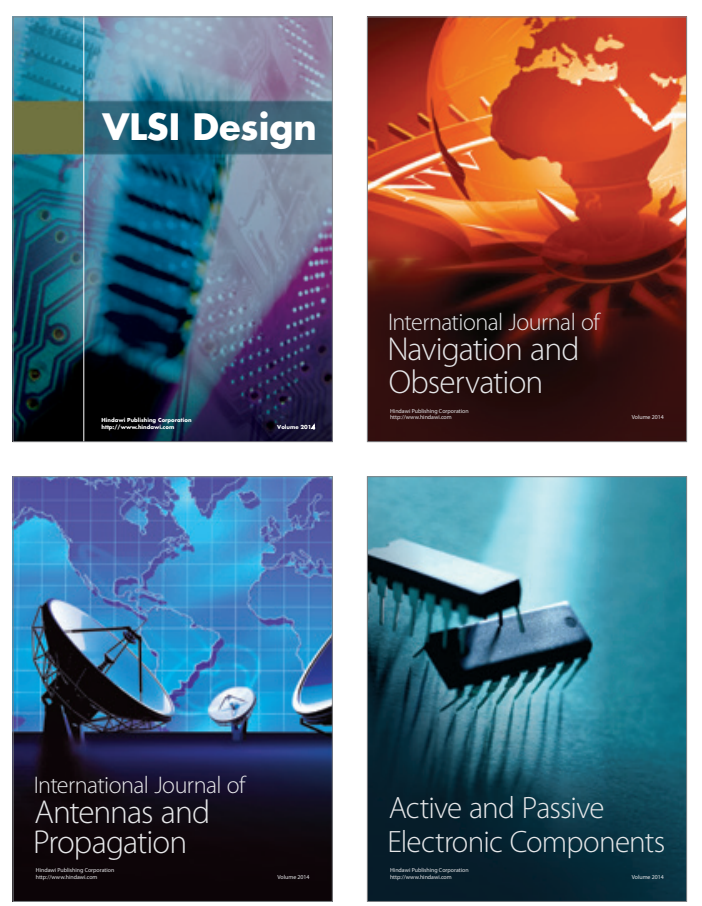
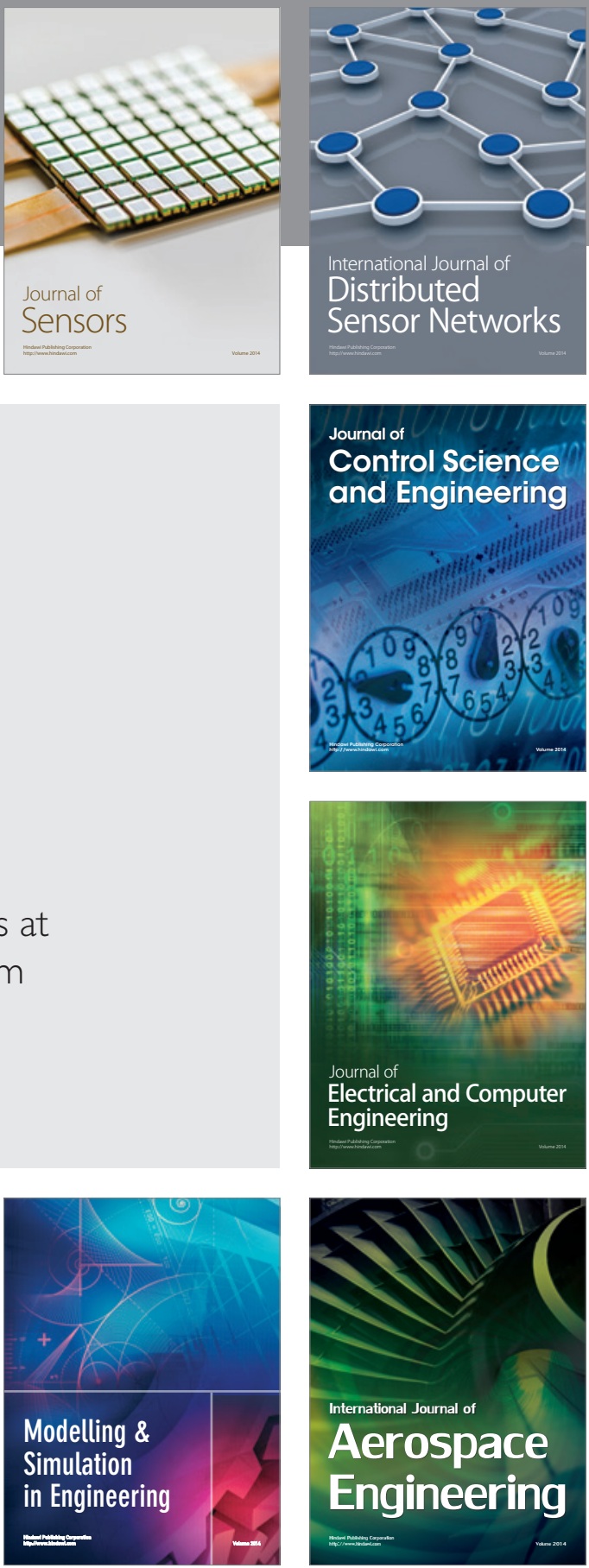

Journal of

Control Science

and Engineering
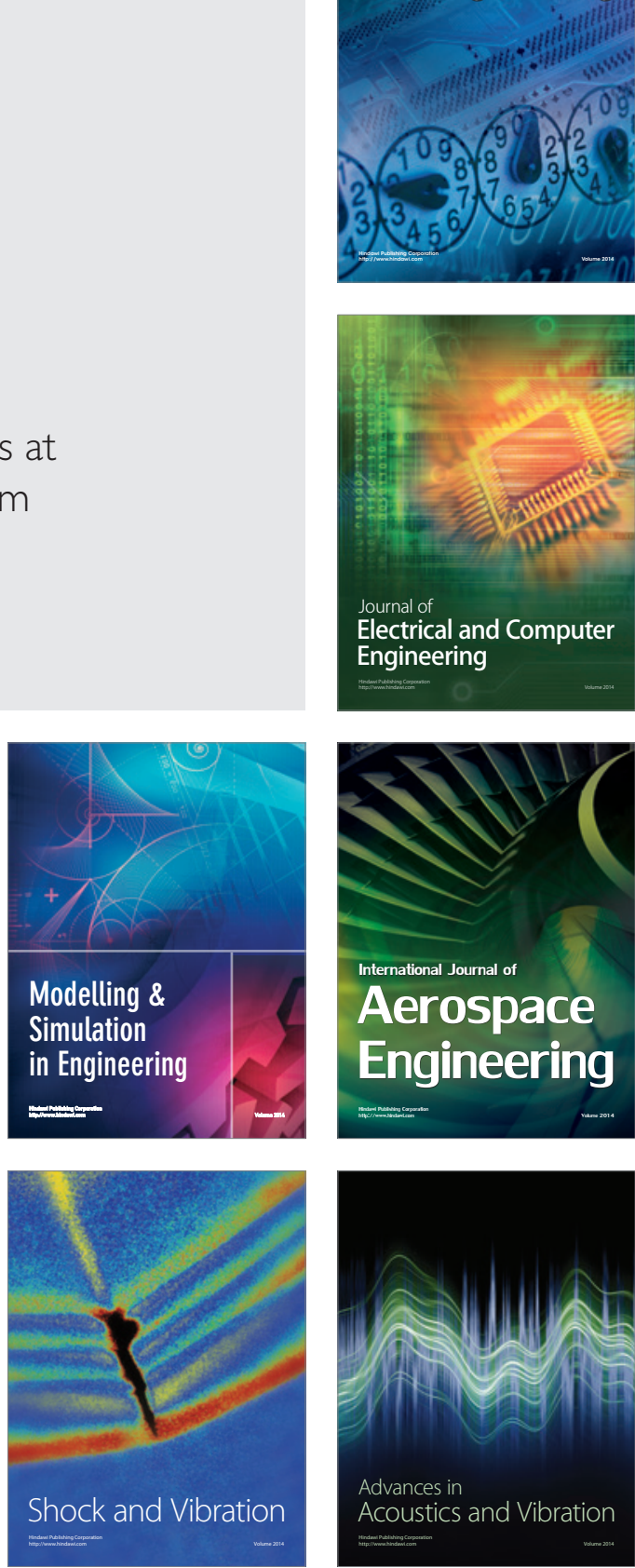